\title{
LA ALTERNANCIA \\ DE LAS PREPOSICIONES EN/A EN VERBOS DE MOVIMIENTO QUE DENOTAN PENETRACIÓN EN EL ESPAÑOL DE MÉXICO
}

\section{Presentación}

El trabajo que presentamos aquí tiene como objetivo mostrar algunas propiedades cognitivas y semánticas de la alternancia $e n / a$ en los complementos locativos que acompañan verbos de movimiento que denotan penetración del tipo entrar, ingresar y meter(se). Según la bibliografía conocida, hay al menos dos ideas muy generalizadas alrededor de esta alternancia: 1) ésta se explica grosso modo como una diferencia en las preferencias dialectales, esto es, en las normas americanas se prefiere el uso de la preposición $a$; mientras que en España, los hablantes prefieren la preposición en. 2) El hablante peninsular al alternar la preposición en por a manifiesta modos distintos de conceptualizar la misma acción. Hay poca o nula referencia a la alternancia de $a$ por en, en normas americanas, ni al hecho de que ésta pudiera presentar, a su vez, un carácter significativo para los hablantes de estas normas. Como consecuencia de lo anterior, este trabajo quiere $a$ ) demostrar que la alternancia de estas preposiciones no puede explicarse como una simple preferencia dialectal, sino que se trata de una estrategia conceptual general de la lengua española, aplicable también a la norma mexicana y, probablemente, a otras normas en mayor o menor medida; b) identificar aquellas pautas para la alternancia no sólo para el verbo prototípico entrar, sino para otros verbos con características afines, aunque más reacios a la alternancia; $c$ ) ofrecer una explicación a la alta frecuencia de la preposición $a$ en la norma mexicana, en contraste con otras normas más conservadoras como la peninsular. 
Notas SObRE LA ALTERNANGIA DE LAS PREPOSICIONES EN/A

Brevemente, exponemos las opiniones que ha merecido, por parte de los gramáticos, la alternancia de las preposiciones $\mathrm{en} / \mathrm{a}$ en construcciones con verbos de movimiento y penetración. Por ejemplo, en un trabajo de corte prescriptivo, Miguel de Toro y Gisbert decía: "entrar a es malísimo. En castellano es entrar en. Hay numerosos ejemplos de este defecto en los escritores que estudio: «entrar a un colegio», «entró a aquella casa», «en ese instante entró a la escena». Lo mismo diremos de «penetraba a la sala»" . También, Valentín García-Yebra considera que el uso de $a$ en lugar de en es un giro habitual en el español de América, "quizá por galicismo: «entrar a la casa», «entrar a la iglesia» (cf. fr. entrer à l'Université, à l'hôpital, à l'Académie, aunque estas expresiones con entrer no tienen propiamente el sentido de penetrar, sino el de "ser recibido en»)"2 y afirma, además, que el español peninsular guarda "fielmente la herencia latina (intrare in Capitolium «entrar en el Capitolio», intrare in rerum naturam «penetrar en la naturaleza de las cosas»), se dice «entrar en casa», «entrar en la iglesia»" (ibid., p. 114), así, el autor coloca esta variación bajo el rubro de incorrección de uso.

Ahora bien, María Luisa López presenta la variación como un fenómeno más recurrente y natural entre los hablantes del español. En las oposiciones facultativas, la autora clasifica la alternancia de las preposiciones $e n / a$ en construcciones con verbos de movimiento cuyo significado no parece ser afectado ${ }^{3}$ :

Algunos verbos, como entrar, penetrar, hacer subir, echary algún otro, pueden construirse con $a \mathrm{o}$ en, constituyendo una oposición facultativa: "El alemán se encogía de hombros y entraba a la casa" (El Farama, pág. 263) / “...entraba en la casa”; "Dejaron a la izquierda la carretera de Loeches y entraban a Torrejón de Ardoz" (El Farama, pág. 330) /...y entraban en Torrejón de Ardoz; caer al agua / caer en el agua; echar a la piscina / echar en la piscina; etc. (ibid., pp. 165-166).

Según explica la autora, "ante las oposiciones facultativas, nos encontramos como en aquellas situaciones del sistema lin-

1 Los nuevos derroteros del idioma, eds. R. Roger y F. Chernoviz, Paris, 1961, p. 192.

2 Claudicación en el uso de las preposiciones, Gredos, Madrid, 1988, p. 113.

3 María Luisa López, Problemas y métodos en el análisis de preposiciones, Gredos, Madrid, 1972, p. 147. 
güístico latino, en el que era indiferente el uso de una determinada construcción o de otra" (p. 208).

Contrario a lo anterior, Samuel Gili Gaya decía que la existencia de este fenómeno se observa desde antiguo en diferentes verbos de movimiento y destaca que la variación de preposiciones no es consecuencia de una alternancia libre, sino que permite representar el modo como los hablantes mentalizan las acciones, es decir, se marca la trayectoria o el movimiento con la preposición $a$ y el punto final de la acción con la preposición $e n$, tal como lo explica a continuación.

En español antiguo, en se combina a menudo con verbos de movimiento, como en latín y otras lenguas romances: "ir en Italia”. La lengua moderna emplea en su lugar la preposición $a$ : pero quedan restos del uso antiguo en expresiones como "pasar de mano en mano", "ir de mal en peor", "ir en casa de su madre" (dialectal); "caer en el agua", "entrar en la iglesia", "subir en un caballo", expresan vagamente el final del movimiento, frente a "caer al agua", "entrar a la iglesia" (textos antiguos y América), "subir a un caballo", con las cuales nos representamos el movimiento mismo. Nótense, asimismo, las frases hechas "caer en gracia", "venir en ayuda"4.

Marcial Morera Pérez señala también que en algunas zonas dialectales en España se suele emplear la preposición $a$ en donde el español normativo exige la aparición de la preposición en, $\mathrm{y}$ al respecto añade: "Aunque de ambas maneras se alude a una misma designación, sin embargo, en las construcciones con $a$ se significa la 'dirección del movimiento', mientras con en pone el acento en los límites del lugar hacia el que se dirige el mismo"s.

En una gramática más reciente, de corte descriptivo, Jacques de Bruyne expone brevemente la particular alternancia de las preposiciones $e n / a$ con verbos de movimiento de la siguiente manera:

Sabido es que con verbos de movimiento se utiliza generalmente la preposición $a$. Tratándose de verbos que denotan penetración (como entrar, ingresar, meter[se], penetrar, etc.), la situación es matizada. En el español europeo se utiliza principalmente la preposi-

${ }^{4}$ Samuel Gili Gaya, Curso superior de sintaxis española, $15^{\mathrm{a}}$ ed., Bibliograf, Barcelona, 1943-1964, § 191.2 (cf. § 189).

${ }_{5}$ Estructura semántica del sistema preposicional del español moderno y sus campos de uso, Excmo. Cabildo Insular de Fuerteventura, Puerto del Rosario, 1988, pp. 149-150. 
ción en (29a, b), mientras que en la América hispanohablante se prefiere $a(29 \mathrm{c}, \mathrm{d})$ :

(29) a. Entró en la Iglesia [RAE 1973:3.11.5i].

b. Penetrar en la casa [DDDLE: 286].

c. Cuando los nazis entraron a París [P. Neruda, Confieso que he vivido].

d. Métanse ustedes dos a mi cama, le dijo Céline [A. Bryce Echenique, Tantas veces Pedro, 103].

e. El reconocimieto [sic] médico es al viejo estilo: tocar timbre, entrar a una sala de espera y someterse a cinco horas de exámenes médicos [Cambio 16, 21-V-1978, 109].

Como muestra (29e), no obstante, también en el español europeo es posible encontrar entrar $a$, pero con un matiz especial de dirección, es decir, que alude al comienzo de la acción de entrar ${ }^{6}$.

Aunque al principio de la cita el autor explica la alternancia como una diferencia dialectal, no tarda en reconocer, con base en la evidencia, que no sólo los hablantes hispanoamericanos, sino que también los peninsulares recurren al uso de la preposición $a$, pero el uso de esta preposición implica un matiz de dirección. La misma opinión ya la ofrecía años antes Manuel Seco cuando se refería a la alternancia de estas preposiciones en construcciones con el verbo entrar: "En España, aunque no es tan extraña la construcción con $a$, su uso tiene un matiz especial de dirección: alude al comienzo de la acción de entrar, mientras que con en alude al término de esa acción"7.

Un examen particular de las estructuras de entrar en/entrar a lo ofrece Ibarretxe-Antuñano ${ }^{8}$ quien analiza cómo entienden los

6 "Las preposiciones", en Gramática descriptiva de la lengua española, dirs. I. Bosque y V. Demonte, Espasa-Calpe, Madrid, 1999, § 10.8.1.1 (las cursivas son mías).

7 Diccionario de dudas y dificultades de la lengua española, $10^{\mathrm{a}}$ ed., EspasaCalpe, Madrid, 1928-1998, s.v. "entrar".

8 En Iraide Ibarrexte Antuñano, "Entering Spanish. Conceptual and semantinc properties of entrar en/a", Annual Review of Cognitive Linguistics, 1 (2003), 29-59, la autora analiza las propiedades conceptuales y semánticas de las estructuras entrar en/entrar a, en hablantes del norte de España, en particular del País Vasco y de La Rioja. En este artículo, la autora argumenta que las preposiciones pueden activar dos sentidos, uno dinámico y otro estático, y que en tales sentidos se ven involucrados varios procesos cognitivos como la relación entre fuerzas dinámicas, metonimia, la deixis, y el ámbito. Nos hemos apoyado, como veremos más adelante, en la noción 
españoles los eventos construidos con el verbo entrarjuntamente con la preposición locativa en y la preposición adlativa $a$ y ofrece los siguientes argumentos en su estudio:

a) un evento con entrar en español se conceptualiza como un proceso de movimiento de traslación con un cruce de frontera. Los factores clave en esta conceptualización son la naturaleza de cruce fronterizo en sí (boundary crossing) y la relación de fuerzas dinámicas (force dynamics) entre las entidades que participan en el evento de entrar ${ }^{9}$. Según la autora, los españoles ponen especial atención en el modo como se lleva a cabo el cruce de fronteras. Si el cruce es suave, es decir, no hay resistencia o esfuerzo por parte de las entidades involucradas por la acción, suele utilizarse la preposición en ("El cuadrado entra en el triángulo"). Por otra parte, si hay alguna resistencia o esfuerzo por parte de los involucrados en el evento de entrada la estructura exigirá la preposición $a$ ("El cuadrado le entra al triángulo") ${ }^{10}$.

b) La elección de una preposición provoca una interpretación diferente de lo que superficialmente parece el mismo evento de entrar. Es decir, los españoles observan diferencias entre un significado dinámico en el que hay un movimiento y un desplazamiento (sentido prototípico), y un significado estático, donde propiamente hay el movimiento y no el desplazamiento, este último sentido es similar al de "caber"11.

de metonimia, pues, como los datos lo indican, es posible que se trate de un mecanismo cognitivo muy utilizado por los hablantes mexicanos.

${ }^{9}$ Véase Leonard Talmy apud I. IbARREXTE-AntUÑano, op. cit., pp. 37-38.

${ }^{10}$ No fue posible aprovechar la noción de "fuerzas dinámicas" tan clara para los datos del español peninsular, aunque sí fue monitoreada en nuestros datos. Los casos del tipo "El cuadro le entra al triángulo", que sugiere que una entidad más grande se mueve hacia una más pequeña, de tal forma que la pequeña queda dentro de la mayor (un significado similar a caber,) y donde se percibe una resistencia o esfuerzo por parte de los participantes involucrados, no pudo ser verificada del todo en los datos de nuestro corpus del español mexicano. No creemos, sin embargo, que este proceso cognitivo no sea aprovechado por los hablantes mexicanos; ocurre que en nuestro corpus no hallamos datos suficientes con frase prepositiva explícita para identificar este proceso con la prominencia que se observa en el trabajo de Ibarretxe-Antuñano, pero habrá que entender que buscamos pautas que expliquen la alternancia en un número mayor de verbos de movimiento, además del verbo entrar.

${ }^{11}$ Cf. Gregory Suy, Sobre las preposiciones directivas en español (a, en) y en portugués (a, em, para) con algunos verbos de movimiento: un análisis comparativo, tesis de maestría, Universiteit Gent, 2010, pp. 72-77. Este autor ofrece una revisión lexicográfica de los sentidos que entrar puede tener en español y en 
c) Hay diferentes mecanismos cognitivos que desempeñan un papel importante para establecer estas interpretaciones, no sólo con las preposiciones alternantes, sino también en una preposición como la metonimia ACTIVITY FOR PLACE, la deixis y el ámbito.

Ahora bien, la permutación de preposiciones en este tipo de verbos en particular no parece del todo libre, como lo deja ver María Luisa López; coincidimos con aquellos que dicen que hay diferencias en el modo de conceptualizar la acción, y este modo se ve reflejado en la selección de una u otra preposición. No obstante, no estamos de acuerdo en que sólo el hablante europeo o peninsular utilice la alternancia como estrategia cognitiva y que el hablante americano prefiera el uso de $a$ de forma generalizada. Los datos que estudiamos muestran que la preposición $a$ no es la preferida en términos cuantitativos para las normas americanas, como lo veremos más adelante y, si bien para los hablantes peninsulares la alternancia no es un incorrección sino un mecanismo cognitivo significativo, también debería serlo para otras normas. Además, en el español de México también encontramos que la alternancia de preposiciones activa otras interpretaciones, aparte de la de movimiento, de las que son corresponsables tanto la preposición como las propiedades semánticas de las entidades locativas, tal como se propone en estudios como los de Iraide Ibarretxe-Antuñano y Gregory Suy sobre el verbo entrar.

\section{CoRpus y METODOLOGía}

Para este estudio hemos recurrido a dos corpus. El primero está conformado por 800 ejemplos con el verbo entrar y un complemento locativo en forma de frase prepositiva introducida por la preposición en o $a$. Los datos proceden de cuatro países, a saber: España, Argentina, Venezuela y México. Estos primeros datos, 200 por cada norma, se obtuvieron de forma aleatoria del Corpus de Referencia del Español Actual (CREA) ${ }^{12}$ de la Real Academia de la Lengua Española. Los medios utilizados

portugués; no obstante, todos o casi todos los ejemplos del español aportados en la sección correspondiente, presentan la preposición en.

${ }^{12}$ Este corpus se puede consultar en la base de datos de la Real Academia Española, en la siguiente dirección: <www.rae.es $>$. 
fueron periódicos y revistas, sin restricción de temas. Adelante, pongo a consideración del lector el Cuadro 1 con los datos de este primer corpus; en él, es claramente observable que, por lo menos cuantitativamente, se tiende al uso de la preposición en. Podemos ver que las normas española ${ }^{13}$ y argentina se muestran más conservadoras que las normas venezolana y mexicana, pero en todas ellas el uso de la preposición en es mayor. Sólo en la norma mexicana se observa un ligero equilibrio en el uso de las preposiciones en cuestión:

\section{Cuadro 1}

Frecuencia de uso de las preposiciones en/a en construcciones con el verbo entrar en cuatro normas del español

\begin{tabular}{lcc}
\hline & $e n$ & $a$ \\
\hline España & $94 \%$ & $6 \%$ \\
& $(184 / 200)$ & $(11 / 200)$ \\
Argentina & $82 \%$ & $18 \%$ \\
& $(164 / 200)$ & $(36 / 200)$ \\
Venezuela & $63 \%$ & $37 \%$ \\
México & $(125 / 200)$ & $(75 / 200)$ \\
& $56 \%$ & $44 \%$ \\
& $(112 / 200)$ & $(88 / 200)$ \\
\hline
\end{tabular}

Puesto que para nuestro estudio sólo nos interesaba la norma mexicana, se conformó un segundo corpus con datos exclusivamente de origen mexicano, ampliamos la muestra de entrar e integramos otros verbos con características sintácticas y semánticas afines a este verbo, tales como meter(se), adentrarse, infiltrar(se), introducir(se), penetrar, ingresar. Los datos se obtuvieron, una vez más, del CREA, pero cabe advertir que, dada la vasta cantidad de casos que arrojaban los verbos entrar, ingresary meter(se), se revisaron todos los temas en medios escritos, pero la búsqueda se res-

13 Los porcentajes de frecuencia de las preposiciones en y $a$ son similares a los reportados por GREGORY SUy, op. cit., p. 130, quien muestra un porcentaje de $90 \%$ para estructuras con la preposición en, y $10 \%$ para estructuras con la preposición $a$ (en construcciones con el verbo entrar en español); por otra parte, reporta que, para el portugués, entrar muestra $75 \%$ con la preposición em, $2 \%$ con $a, 22 \%$ con para y $1 \%$ con para dentro de. 
tringió a cinco subtemas ${ }^{14}$; con los verbos adentrarse, introducirse, penetrare infiltrarse se revisaron todos los medios escritos y temas. El Cuadro 2 muestra el número de ejemplos obtenidos con cada una de las entradas léxicas seleccionadas:

CuAdro 2

Distribución porcentual de los verbos de movimiento seleccionados que denotan penetración

\begin{tabular}{ll}
\hline Verbo & Cantidad \\
\hline Entrar & $41 \%(617 / 1495)$ \\
Meter(se) & $17 \%(253 / 1495)$ \\
Introducir(se) & $14 \%(203 / 1495)$ \\
Penetrar & $12 \%(181 / 1495)$ \\
Ingresar & $11 \%(157 / 1495)$ \\
Adentrar(se) & $3 \% \quad(52 / 1495)$ \\
Infiltrar(se) & $2 \% \quad(32 / 1495)$ \\
\hline
\end{tabular}

Como se aprecia en el Cuadro, el verbo entrar ofrece el mayor número de construcciones documentadas en todo el corpus $y$, por ende, no es de extrañar que este verbo sea el que muestre mejor el fenómeno que nos interesa.

Ahora bien, este segundo corpus constó de 1495 testimonios de oraciones donde se alternan las preposiciones en y $a$. De este total, 901 corresponden a construcciones con la preposición en, mientras que las 594 restantes se construyeron con la preposición $a$, así hemos podido verificar que entre todos estos verbos de movimiento que denotan penetración, la estructura más productiva es aquélla con la preposición en y no con la preposición $a$. Tal como lo muestra el Cuadro 3:

14 Para el fichado de estos verbos, entrar, meter(se) e ingresar, se revisaron todos los medios escritos (esto es, libros, revistas, periódicos, con excepción de miscelánea) y se eligieron, de forma aleatoria, los primeros cinco subtemas de los siguientes temas: 1. Ciencia y tecnología; 2. Ciencia Sociales, creencias y pensamiento; 3 . Política, economía, comercio y finanzas; 4 . Artes; 5. Ocio, vida cotidiana; 6 . Salud, 7. Ficción, con la finalidad de mantener la variedad de medios y temáticas que gozaron el resto de los verbos (penetrar, adentrarse, introducirse e infiltrarse). 
Cundro 3

Distribución de la frecuancia relativa de las preposiciones en/a

\begin{tabular}{llc}
\hline Verbo & \multicolumn{1}{c}{ en } & \multicolumn{1}{c}{$a$} \\
\hline Adentrarse & $96 \%(50 / 52)$ & $4 \%(2 / 52)$ \\
Infiltrar(se) & $84 \%(27 / 32)$ & $16 \%(5 / 32)$ \\
Penetrar & $82 \%(148 / 181)$ & $18 \%(33 / 181)$ \\
Introducir(se) & $80 \%(163 / 203)$ & $20 \%(40 / 203)$ \\
Meter(se) & $65 \%(172 / 253)$ & $35 \%(81 / 253)$ \\
Entrar & $51 \%(316 / 617)$ & $49 \%(301 / 617)$ \\
Ingresar & $17 \%(26 / 157)$ & $83 \%(131 / 157)$ \\
Total & $60 \%(902 / 1495)$ & $40 \%(593 / 1495)$ \\
\hline
\end{tabular}

Ahora bien, el análisis se desarrolla en un marco cognitivista. Partimos de establecer una estructura conceptual básica, aplicable al tipo de verbos de movimiento en cuestión, con base en sus características léxico-semánticas comunes. Según los distintos autores antes referidos, la alternancia de las preposiciones en hablantes peninsulares refleja modos distintos de conceptualizar un mismo evento, en términos de poner en perfil alguno de los elementos que conforman la estructura conceptual y dejar otros en el fondo ${ }^{15}$.

Según los datos observados, los hablantes mexicanos ciertamente establecen diferencias en el modo de conceptualizar los eventos de entrada, perfilando así el movimiento o el punto de destino, pero apoyados a su vez por el modo como conceptualizan los referentes locativos. De ahí que hemos recurrido a la herramienta teórica de Esquema de imagen de Mark Johnson ${ }^{16}$ y,

${ }^{15}$ Las nociones de perfily fondo son utilizadas según lo propuesto por RONALD W. LANGAGKer, Foundations of cognitive grammar: Theoretical prerequisites, Stanford University Press, Stanford, 1987, p. 490. Un perfil se define como una entidad designada por una estructura semántica, y funciona como el punto focal dentro de la escena objetiva alcanzando un grado de protagonismo en un nivel de organización figura/fondo (de ahí que los elementos perfilados se representan en líneas gruesas).

16 The body in the mind. The bodily basis of meaning, reason, and thought, University of Chicago Press, Chicago, 1987. Los esquemas de imágenes se pueden definir como un complejo unificado de propiedades que organizan la experiencia y comprensión humanas, y manifiestan una pauta repetida que emerge de los movimientos en el espacio y de la experiencia en la manipulación de objetos, de las interacciones perceptivas. Los esquemas de 
en particular, la noción del esquema contenedor (container) para caracterizar las entidades locativas con los siguientes elementos estructurales: un punto interior, uno exterior y un límite (o varios límites) que separa a ambos puntos. Este esquema de imagen activaría las diferencias entre lugares cerrados (contenedor o recipiente) y lugares abiertos (no contenedor, no recipiente). Ahora bien, la virtud del esquema de imagen es que se constituye de pocos componentes, los más básicos que bien pueden ajustarse tanto a estructuras de movimiento real como figurado, por ejemplo, contrástense las siguientes estructuras: "eso no me entra en la cabeza" / "eso no me entra en la mente", aunque la mente sea una entidad más abstracta que cabeza, el hablante la conceptualiza como un contenedor o recipiente donde se ubican los pensamientos, saberes o creencias. La hipótesis que proponemos, entonces, es que la elección de en o $a$ obedece en gran parte a la capacidad del hablante de conceptualizar o no al locativo como un contenedor (esquema de imagen: contenedor o recipiente) y, en consecuencia, poner en perfil el cruce de frontera (esquema de imagen: límite ${ }^{17}$. Así, con un locativo-contenedor se pone en perfil el cruce de la frontera y se selecciona la proposición en; mientras que si tenemos un locativo-no contenedor no es posible poner en perfil el momento del cruce de frontera y sólo se perfila el movimiento hacia lo que se supone que es el interior del locativo, por tanto, se selecciona la preposición $a$ con matiz de dirección.

Por otra parte, nos hemos particularmente apoyado en el estudio de Iraide Ibarretxe-Antuñano, quien hace patente que no todos los casos representan un movimiento que implique desplazamiento, es decir, un cambio de lugar y explica que la elección de la preposición activa otros significados en que participan otros mecanismos cognitivos para la interpretación de la estructura. En nuestro estudio sólo hemos recurrido a la noción

imágenes constan de pocos elementos básicos relacionados por estructuras definidas, pero con cierta flexibilidad; tal flexibilidad permite que un esquema sea productivo y genere diversas extensiones metafóricas. Agradezco a la doctora Blanca Elena Sanz su recomendación de incluir esta herramienta cognitiva en el análisis.

17 Véase C. Bretones \& I. Ibarretxe, "The construction salir-de in Spanish. How Spanish conceptualise exiting events", en Construction grammar: Back to the roots, eds. M. Fried \& H. Boas, J. Benjamins, Amsterdam-Philadelphia (en prensa), apud I. IbARRETXE-Antuñano, op. cit., pp. 35-37. 
de metonimia ${ }^{18}$ que sugiere Ibarretxe-Antuñano, en particular, la de LUGAR POR ACTIVIDAD. Este proceso cognitivo, según veremos más adelante, es altamente productivo entre los hablantes mexicanos y no sólo concentra muchos de los ejemplos con la preposición $a$ sino que muestra otras extensiones metonímicas no abordadas en el estudio de la mencionada autora.

\section{PROPIEDADES CONCEPTUALES Y SEMÁNTICAS}

DE LAS ESTRUCTURAS DE LOS VERBOS DE MOVIMIENTO

Y PENETRACIÓN EN EL ESPAÑOL DE MÉXICO

\section{Movimiento y desplazamiento real}

Los verbos analizados en este trabajo muestran como característica común un complemento locativo introducido por una preposición, según reconocen las diferentes gramáticas; esta preposición puede ser en o $a$. En segundo lugar, los verbos seleccionados significan, grosso modo, "moverse hacia el interior de algo cruzando un límite", así componencialmente implican un objeto que se mueve $(\mathrm{OM})$, un movimiento o trayectoria y un punto de destino (PD) o meta penetrable flanqueada entre límites. Podríamos decir que todos los verbos que se analizarán comparten el Esquema 1 básico:

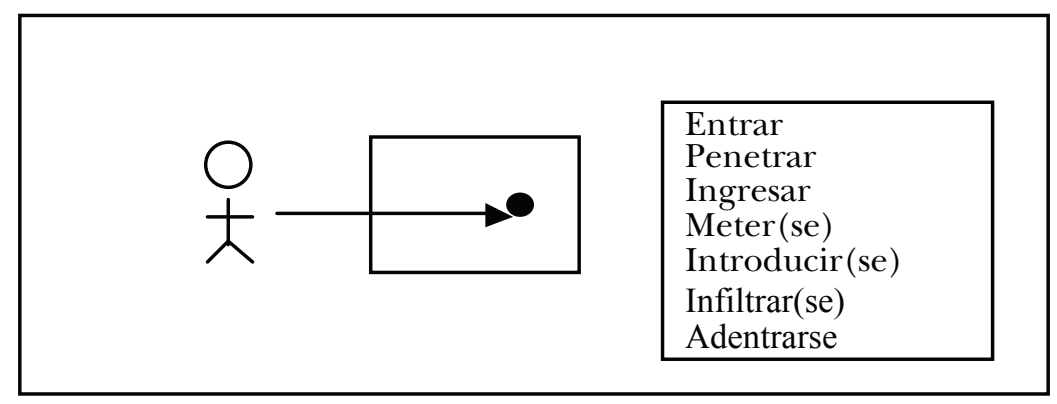

Esquema 1. Esquema básico de los verbos de movimiento

En el Esquema 1 se representa con una flecha el movimiento y con un cuadro el punto de destino o meta flanqueado por lími-

18 Aprovecho para agradecer a uno de los lectores anónimos por la sugerencia de aprovechar la noción de metonimia, propuesta en IbarretxeAntuñano, para economizar y dar mayor claridad al trabajo. 
tes, el movimiento termina precisamente en el interior de esta locación; por último, el punto muestra la posición resultante del objeto de movimiento. El Esquema presenta elementos básicos para todos los verbos y como ilustraremos a continuación, alguno de estos componentes es perfilado y formalmente marcado por medio de la elección de una de las preposiciones en cuestión.

Ahora bien, si la alternancia obedece a formas distintas de conceptualización de la acción, como lo han hecho notar los gramáticos, se podrían ofrecer al menos dos esquemas conceptuales básicos, uno para la construcción verbo de movimiento y penetración + en y otra para la construcción verbo de movimiento y penetración $+a$.

a) Verbo de movimiento + en

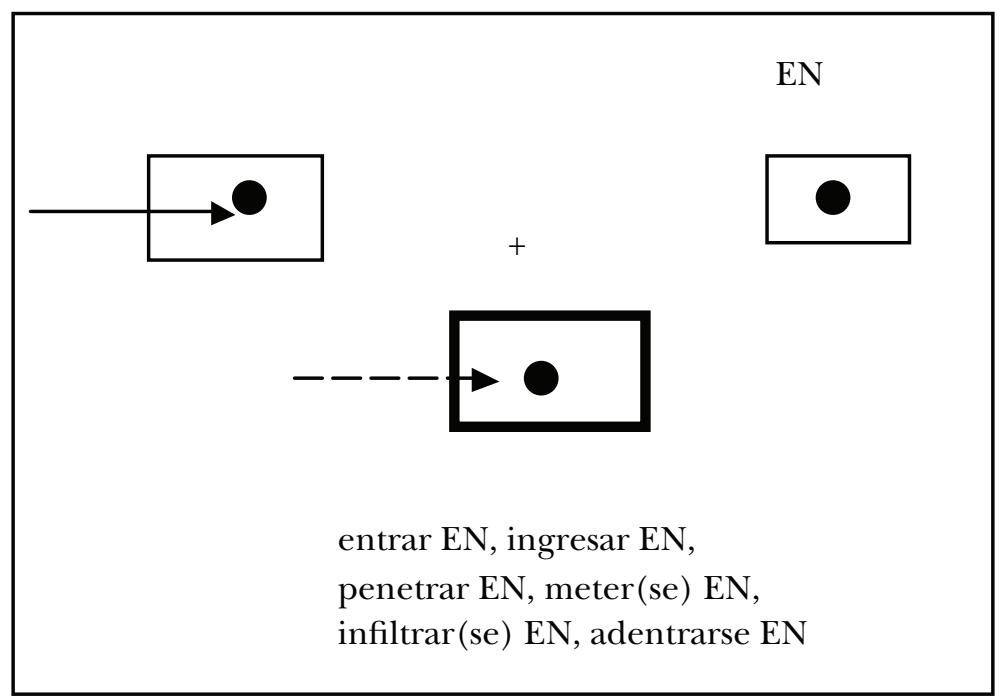

ESQUEMA 2

En este Esquema está la suma de los elementos propios del verbo de movimiento y penetración (supra, Esquema 1) y la idea de interioridad de un espacio expresada por la preposición en. Como resultado, el hablante pone en perfil el cruce del límite del PD de modo que el movimiento finaliza en el interior de éste. Miremos los siguientes ejemplos en (1) y el Dibujo 1 que les sigue: 
(1) a. Momentos más tarde se introdujeron en el cráter para extraer el azufre que buscaban (Ricardo Torres Nava, La conquista del Éverest, 1990).

b. Además de su importancia como factor esencial de salud, la luz del sol suministra iluminación, y la cantidad de esta luz que entra en una habitación controlará el grado de brillantez y alegría de la misma (Susana Rosales Barrera, Fundamentos de enfermería, 1982).

c. La sustancia puede penetrar en las células sensoriales y estimularlas directamente o puede reaccionar con algunas en el receptor para producir una o más sustancias que estimulen las células sensoriales (Fidel A. Cabezas Melara, Introducción a la entomología, 1996).

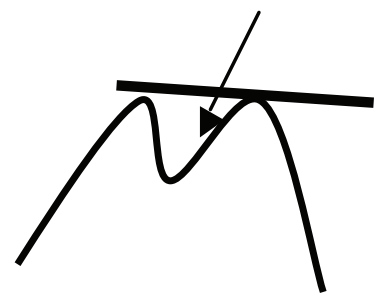

...se introdujeron/ entraron/ penetraron/ en el cráter...

Dibujo 1

A diferencia de los típicos verbos de movimiento como llegar, $i r$, venir, caminar, etc., cuyo final del movimiento queda libre a la interpretación (esto es, que podemos decir "al fin llegué a casa" y pensar que penetramos el punto de destino o que simplemente coincidimos con él); en nuestros verbos el movimiento debe rebasar el límite que separa el afuera y el adentro; de ahí que recurramos a la preposición en para perfilar el PD y el cruce del límite que refuerza la idea de penetración.

Visto lo anterior, pasemos ahora a la combinación verbo de movimiento más la preposición $a$.

b) Verbo de movimiento $+\mathrm{a}$

Obsérvese la suma de los elementos propios del grupo verbal y la idea de dirección de la preposición $a$; como resultado, podemos decir que el movimiento es el elemento puesto en perfil por 


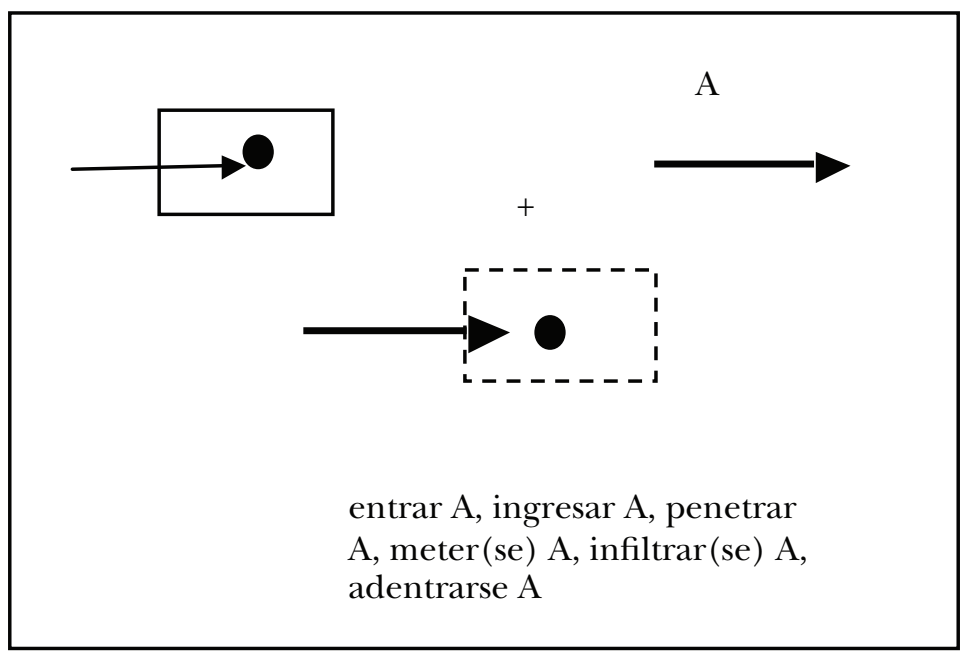

EsQUema 3

el hablante. La preposición $a$, en contraste con otras preposiciones directivas, es indiferente al expresar rebasamiento o no de un límite como ocurre con la preposición hasta, pero manifiesta un alcance del límite más determinado que las formas para o hacia, lo cual le permite verificar la posición final del objeto de movimiento, aunque no la idea de penetración del mismo:

(2) a. Esperaba, al llegar, subir despacio las escaleras para no fatigarse a lo pendejo, entrar sin hacer ruido, desnudarse lentamente, meterse a la cama, empezar a despertarla con suaves besos detrás de las orejitas y... (Daniel Leyva, Una piñata llena de memoria, 1984).

b. Luego penetraron los alpinistas al glaciar también llamado Rongbuk y llegaron hasta la frontera entre Nepal y Tibet (Ricardo Torres Nava, La conquista del Éverest, 1990).

c. El fenómeno, que ayer ingresó al Golfo de Honduras, ocasionará lluvias en Quintana Roo (Diario de Yucatán, 4 de julio de 1996).

$d$. No entró por el lugar señalado para iniciar el recorrido a las ruinas, rodeando éstas se introdujo a la zona por su parte posterior (Antonio Velasco Piña, Regina, 1987).

Tomando como ejemplo el caso de $(2 a)$, el objeto de movimiento no penetra el PD (cama), sólo se posiciona sobre él. La elección de $a$ podría deberse, en éste y otros casos, a que el hablante no visualiza al locativo o PD como un contenedor ni 


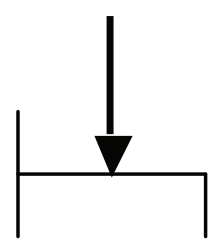

...meterse/ introducirse / entrar / penetrar $a$ la cama...

Dibujo 2

observa el cruce de un límite; en consecuencia no hay esta idea de penetrabilidad, sólo de coincidencia.

De lo anterior obtenemos dos esquemas de imagen operando en la cognición de lo que parece ser el mismo evento: uno, en donde al perfilar los límites que circunscriben el espacio en cuyo interior se posicionará el OM, el locativo se conceptualiza como contenedor; otro, en donde no es posible perfilar los límites del referente locativo, por lo cual el movimiento adquiere mayor prominencia frente al PD, de ahí que proponemos los Esquemas 4 y 5 para la elección de en y $a$, respectivamente:

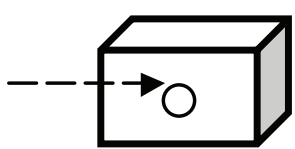

...entrar en la célula...

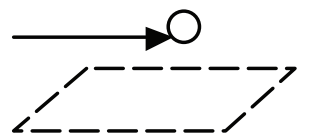

...meterme a un llano...

ESQUEMA 4

ESQUEMA 5

Estos dos esquemas se ajustan al sentido básico del verbo de movimiento. En el Esquema 4, el OM cruza claramente los límites que flanquean el PD, se entiende el paso de un punto exterior a un punto interior -en otras palabras, el locativo ha sido penetrado-; mientras que en el Esquema 5, en el OM no hay un cruce del límite, sino sólo un movimiento hacia lo que se supone que es un punto interior del PD.

Bien se puede notar que sólo hemos ofrecido ejemplos que hacen referencia a un movimiento real. Pasaremos a mostrar cómo se comportan las estructuras que remiten a un movimien- 
to figurado o nocional. Las diferencias entre este sentido real del movimiento y un sentido nocional dependen en mucho de las características semánticas de los referentes locativos.

\section{Movimiento figurado}

Todos los verbos estudiados arrojaron ejemplos que remiten a un movimiento figurado. En estos casos el hablante selecciona la preposición en para dar a la entidad locativa el sentido de lugar o espacio en donde el objeto de movimiento se posiciona, en otras palabras, le otorga dimensionalidad. Estas construcciones son consideradas generalmente como casos de metáfora verbal. Según explica Beatrice Lamiroy ${ }^{19}$, la metáfora ha sido un mecanismo altamente productivo en el ámbito de los verbos de movimiento y ha dado lugar a estructuras en las que se desarrollan conceptos más abstractos derivados de otros conceptos complejos procedentes de la espacialidad lingüística. Para que la metáfora sea exitosa, la autora pone especial atención en dos factores: primero debe haber un paralelismo sintáctico entre ambos tipos de estructura, la metafórica y la espacial; segundo, debe producirse una cierta rigidez sintáctica en las estructuras con menos posibilidades de variación en contextos figurados. Pongamos a consideración los siguientes ejemplos:

(3) a. Los legos llegamos a comprender el origen de los problemas, aprendemos y nos adentramos, por ejemplo, en la situación de los desiertos mexicanos, su riqueza, las formas tradicionales de explorar sus recursos (Proceso, 17 de noviembre de 1996).

$b$. Como consecuencia de ello, la fotosíntesis y el crecimiento se interrumpen y el resto de los tejidos vivos de las plantas entran en un estado de desecación parcial y reducción de la respiración... (Carlos Vázquez Yanez, Cómo viven las plantas, 1987).

c. En España, la ultraderecha intentó infiltrarse en el movimiento ecologista (Proceso, 22 de diciembre de 1996).

19 "Les verbes de mouvement emplois figurés et extensions métaphoriques", en Langue français: L'expression du mouvement, ed. C. Vandeloise, Larousse, Paris, 1987. También, véase el trabajo de Jean-Paul Boons, "La notion sémantique de déplacement dans une classification syntaxique des verbes locatifs", en Langue français: L'expression du mouvement. 
d. Creemos, con Sartre, que en determinada medida el cuerpo no es "diferente del orden absoluto del mundo", y esto tanto con referencia a los sectores que no vivenciamos y que únicamente a través de un rodeo, por así decir, ingresan en el orbe de la subjetividad, como con referencia al cuerpo en total (Aída Aisenson Kogan, Cuerpo y persona. Filosofia y psicología del cuerpo vivido, 1981).

En los ejemplos anteriores se observa el isomorfismo sintáctico con las estructuras espaciales; así pues, las nocionales presentan un objeto que se mueve y un complemento preposicional que actúa como base de localización. No obstante, es posible, la alternancia de en por $a$ : "entran $a$ un estado de desecación parcial y reducción de la respiración", "nos adentramos $a$ la situación de los desiertos mexicanos", "infiltrarse al movimiento ecologista", "ingresan al orbe de la subjetividad" 20 . Ahora bien, hay que destacar que sólo fue posible encontrar estructuras con entrar y meter $(\mathrm{se})^{21}$ con frases nominales escuetas en donde es invariable la preposición en, como en los ejemplos de (4):

(4) a. Es un diario que trata con seriedad los asuntos públicos, pero que años más tarde entra en crisis, hasta que en 1895 lo adquiere Adolph S. Ochs y aumenta su tiraje (Eulalio Ferrer, Información y comunicación, 1997).

$b$. Los estrógenos provocan que la cerda entre en celo e inducen la liberación de LH, con lo cual determinan el momento de la ovulación (Javier de J. Valencia Méndez, Fisiología de la reproducción porcina, 1986).

c. Escritor: No se meta en líos, compadre. Déjelo. Al rato se calmará (Wilebaldo López, Vine, vi... y mejor me fui, 1975).

Podemos comprobar que debido a la desviación semántica que sufre la construcción, su configuración sintáctica adquiere

${ }^{20}$ Lo mismo observa Elisa BARRAjón López en "El criterio de rección preposicional de los usos nocionales y locales del verbo de movimiento meter en: ¿un proceso de metaforización?”, en Estudios de Lingüistica, 2002, núm. 16, p. 11 (ed. electrónica, Espagrafic); la autora observa que el verbo meter, en usos nocionales, conserva las mismas características sintácticas que las formas rectas, pero dependiendo del grado de gramaticalización y la naturaleza más o menos abstracta será que se restrinja o no la alternancia de en por otras preposiciones o locuciones preposicionales.

${ }^{21}$ Ejemplos como "meter o entrar en calor/en vigor/en funciones/en contacto" son muy comunes en nuestro corpus y cubren un alto número de ejemplos. 
una mayor rigidez, por lo cual no es posible alternar en por $a$ : *entra a crisis, *entra a celo, se mete *a líos. No obstante, estos casos de rigidez sintáctica sólo se presentan en estos dos verbos, pues no fue posible documentar este fenómeno con otros verbos de movimiento: * penetrar en celo, *adentrarse en crisis, *ingresar en función, *se introdujo en contacto, *se infiltró en calor.

\section{Estructuras con a: sentido incoativo del verbo}

Particularmente, los verbos entrar, meter(se) e ingresar pueden expresar un sentido incoativo que permite seleccionar la preposición $a$. Pero no sólo se trata de la preposición, sino de la naturaleza del complemento locativo. Llama la atención que estas entidades suelen remitir a procesos o actividades; de hecho, varias estructuras presentan sustantivos deverbales como en los ejemplos de (5):

(5) a. En 1939, Wallerstein hizo una película experimental con varios conocidos, antes de entrar a la producción definitiva (Paulo Antonio Paranaguá, Arturo Ripstein, 1997).

$b$. La carrera de investigador científico generalmente requiere primero el estudio de una licenciatura... Esto toma entre cinco y seis años, de modo que el estudiante ya tiene de 23 a 26 años de edad cuando ingresa a sus estudios de posgrado (Ruy Pérez Tamayo, Ciencia, paciencia y conciencia, 1991).

En la preposición a no se activa el contenido semántico de "dirección", sino el de "propósito" o "finalidad", que es característico en las preposiciones adlativas. Por otra parte, el verbo ya no expresa un movimiento hacia el PD, sino que adquiere un sentido incoativo respecto a las actividades que se llevarán a cabo. Así, no es de extrañar que estos verbos puedan conmutar por uno con significado incoativo del tipo comenzar, iniciar o empezar. "el estudiante ya tiene de 23 a 26 años de edad cuando ingresa a/comienza sus estudios de posgrado", "Wallerstein hizo una película experimental con varios conocidos, antes de entrar a/comenzar la producción definitiva”.

Sentido incoativo y procesos metonímicos. Siguiendo con estructuras con $a$, observamos que no todas ofrecen un sustantivo deverbal. 
Algunas presentan, como puntos de destino, instituciones $\mathrm{u}$ organizaciones que aluden de forma implícita a las acciones o actividades que se llevan a cabo en ellas, como los ejemplos siguientes de (6):

(6) a. Poco antes de la muerte de Fernando -mediados de enero del 68- entramos a la universidad (Marco Antonio Campos, Que la carne es hierba, 1982).

b. Por el lado materno, sigue, hubo un catalán sufrido que se metió a la Armada, José Enrique Soler (Proceso, 13 de octubre de 1996).

c. Por esa época se permitió a las mujeres ingresar a la Academia de San Carlos (Julián Matute Vidal, Perfil del mexicano, 1992).

d. Pero en el texto de la denuncia formal de la fiscalía no aparece ningún cargo por "silenciar enemigos" y sólo hay uno por soborno, el muy conocido caso de Claudio de la $\mathrm{O}$, agente de la oficina Federal de investigaciones (FBI) que se infiltró al cartel del Golfo supuestamente simulando ser corrupto (Proceso, 13 de octubre de 1996).

Los ejemplos no expresan propiamente un sentido de penetración. Según la hipótesis de Ibarretxe-Antuñano la elección de $a$ se podría explicar en términos de metonimia, en particular de "actividad por el lugar" (activity for place) ${ }^{22}$, así es posible pensar en acciones o actividades: "entramos [a estudiar] a la universidad", "un catalán sufrido que se metió [a servir] a la Armada", "se permitió a las mujeres ingresar [a pintar/a estudiar] a la Academia de San Carlos" ${ }^{23}$. Este tipo de ejemplos son muy comunes con los verbos entrar, meter(se) e ingresar.

Sumado a lo anterior, encontramos que el hablante mexicano extiende este mecanismo metonímico todavía más al involucrar no sólo un lugar, sino un objeto o entidad particular para aludir una acción o actividad (parte por el todo/objeto por actividad), tal como se ejemplifica en (7):

22 Op. cit., p. 47.

${ }^{23}$ Un caso contrario, "actividad por lugar", sería el ejemplo siguiente: "Puede ir de oyente, o nomás meterse a las clases. Así van muchos" (Emilio Carballido, Soñar la noche, 1994), por el contexto, a las clases pudiera remitir a "oír", pero la expresión nomás motiva a reinterpretar "las clases" como lugar o lugares "los salones", en otras palabras, se puede invitar a escuchar las clases o sólo a permanecer en los salones en donde se imparten esas clases. 
(7) a. Por fin el Arpa llegó a saludar al gran jefe de la palomilla -¡órale!, ¡órale!, ¿ya listo para entrarle a los cocolazos?-, lo saludó con admiración y entusiasmo (Arturo Azuela, La casa de las mil vírgenes, 1983).

$b$. ...se treparon en los dos autos, llenos de cuates, y despacio, nada de meterle al fierro y darnos en la madre (Rafael Ramírez Heredia, El Rayo Macoy y otros cuentos, 1984).

c. ...ps, casi todos jugamos así fútbol pero... ps, salemos de jugar $[$ sic] y a... a entrarle a la botella, ps, aquí... aquí..., se es el deporte que hay: el jaibol y el...(DEM $)^{24}$.

Los sustantivos como cocolazos, el fierro, la botella no son vistos como locaciones propiamente dichas, sino que son expresiones metonímicas de acciones determinadas, pelear, acelerar, beber y enredar, respectivamente, que requieren de la preposición $a$ para entenderse como tales.

En otros ejemplos es posible observar nombres que denominan oficios, los cuales también remiten a actividades particulares, como en:

(8) a. Y así por arte de magia lo transportó por los aires hasta un remoto país denominado México, y que lo mete a periodista, ¿tú crees? (Tomas Mojarro, Yo, el valedor ly el Jerásimo], 1985).

b. Esta actitud no fue derrotista, sino de preocupación, a pesar de que las personas que lo presenciaron, siempre me dicen que por qué me asusté tanto en ese momento, sin darme cuenta que quien se mete a casquivano debe traer bien amarrados los calzones (Sealtiel Alatriste, Por vivir en quinto patio, 1985).

\section{Sentido de aproximación}

Los casos con penetrar, introducir, adentrarse o infiltrarse que no suponen un movimiento con desplazamiento ofrecen más una idea de "aproximación" al conocimiento de la entidad expresada por el locativo, tal como se manifiesta en los ejemplos siguientes:

${ }^{24}$ El ejemplo fue obtenido del Corpus del Diccionario del español de México (DEM) de El Colegio de México. 
(9) a. Otra vez Carlos Olmos nos introduce a un hogar del sureste, donde los secretos de familia provocan el enfrentamiento y el conflicto que cambiará las relaciones de los personajes (Proceso, septiembre de 1996).

b. Si profundizamos adentrándonos a la maraña política y agudizamos la mente observadora y crítica, podríamos llegar a la deducción de que tal publicidad fue obra de Zedillo y Madrazo ("Nuestro idioma y su uso", Diario de Yucatán, 24 de julio de 1996).

c. Rafael Luviano Delgado... considera que ese proyecto surgió a partir de la ineficiencia demostrada por la policía capitalina y que su realización se plantea como la alternativa más viable para combatir la delincuencia, la cual ha infiltrado a los cuerpos policiacos (Proceso, 26 de enero de 1997).

\section{Conclusiones}

En el desarrollo de este trabajo hemos observado que, por lo menos cuantitativamente, en la norma mexicana (y en otras normas americanas) no se ha desplazado del todo el uso de en por $a$; así las cosas, no es suficiente decir que la alternancia es resultado de preferencias dialectales. Según el análisis de los datos, la elección parece obedecer, por un lado, a la capacidad del hablante de conceptualizar el locativo como un contenedor que permite perfilar el cruce de límite y su formalización con la preposición en. Por otro lado, si el locativo no es conceptualizable como un contenedor, se tiende a perfilar el movimiento, quedando el cruce del límite en el fondo; en consecuencia, el hablante selecciona la preposición $a$.

Ahora bien, el análisis de los datos del español de México mostró también que la alternancia de las preposiciones sí deriva en cambios de significados - hablamos en particular del paso del sentido de "movimiento" a uno "incoativo" u "aproximativo"-; la responsabilidad de este cambio no recae únicamente sobre la preposición $a$, sino conjuntamente con el tipo de locativo que permite reinterpretar el significado de $a$ con sentido "directivo" al de "propósito". Como los datos han hecho ver, este sentido se manifestará altamente potencializado por un mecanismo cognitivo de metonimia que permite que entidades locativas remitan implícitamente a actividades o acciones, ya sea a partir de un lugar, objeto o nombre de oficio. 
Así, hemos querido demostrar, por un lado, que la alternancia de las preposiciones $e n / a$, en la norma mexicana, es tan significativa conceptualmente como en el español peninsular; por otro lado, confirmamos la argumentación de IbarretxeAntuñano para los casos de alternancia en los hablantes del norte de España ${ }^{25}$ : es posible que la selección de una u otra preposición active nuevas interpretaciones de los enunciados, por tanto, la alternancia debería considerarse una estrategia cognitiva-semántica más general de la lengua española.

Cristina Eslava Heredia Universidad Autónoma de Aguascalientes 